\title{
Gene expression and effects of orally active derivatives of fluoropyrimidine on gastric and colorectal cancer
}

\author{
SATOSHI ARAKAWA ${ }^{1}$, SOJI OZAWA ${ }^{2}$, JIN KAWASE ${ }^{1}$, HISANORI OSHIMA ${ }^{1}$, \\ HIDETOSHI NAGATA $^{1}$, KOJI ATSUTA ${ }^{1}$ and SHUNJI UMEMOTO ${ }^{1}$ \\ ${ }^{1}$ Department of General and Gastrointestinal Surgery, School of Medicine, Fujita Health University, Aichi 454-8509; \\ ${ }^{2}$ Department of Gastroenterological Surgery, Tokai University School of Medicine, Kanagawa 259-1193, Japan
}

Received September 9, 2009; Accepted December 12, 2009

DOI: 10.3892/etm_00000051

\begin{abstract}
The effects of chemotherapy on gastrointestinal cancer are influenced by the chemotherapeutic sensitivity of the cancer cells. Determining the expression of genes related to chemotherapeutic sensitivity has been used as a molecular method. The aim of the study was to clarify the relationships between the expression of genes related to chemotherapeutic sensitivity and the effects of orally active derivatives of fluoropyrimidine on gastric and colorectal cancer. Forty-five patients who underwent adjuvant chemotherapy containing orally active derivatives of fluoropyrimidine after undergoing curative surgery for gastric or colorectal cancer were enrolled. Twenty-four patients had colorectal cancer and 21 patients had gastric cancer. Total RNA was extracted from formalin-fixed, paraffin-embedded specimens of the resected tumors, and the expression of 11 genes was measured using the RT-PCR method. We then analyzed the relationships between the gene expression and the postoperative relapse rate as well as the relationships between clinicopathological factors and postoperative relapse rate. The median observation period of the subjects was 41 months. Twelve out of the 21 gastric cancer patients (57\%) and 11 out of the 24 colorectal cancer patients (46\%) relapsed. Although the results of a univariate analysis revealed that expression of none of the evaluated genes was related to relapse in the gastric cancer patients, excision repair cross-complementing gene 1 (ERCC1) overexpression was related to the relapse rate in colorectal cancer patients $(\mathrm{p}=0.023)$. When 1.295 was set as the cut-off value for ERCC1 overexpression using the receiver operating characteristic (ROC) curve, $67 \%$ of patients with ERCC1 overexpression and $25 \%$ of patients without ERCC1 overexpression relapsed. The relapse-free survival rate was lower in the group with ERCC1 overexpression than in the group without ERCC1
\end{abstract}

Correspondence to: Professor Soji Ozawa, Department of Gastroenterological Surgery, Tokai University School of Medicine, 143 Shimokasuya, Isehara, Kanagawa 259-1193, Japan

E-mail: sozawa@tokai.ac.jp

Key words: excision repair cross-complementing gene 1 overexpression, relapse, colorectal cancer, fluoropyrimidine overexpression $(\mathrm{p}=0.046)$. ERCC1 overexpression appears to be a useful predictor of relapse in colorectal cancer patients receiving adjuvant therapy with regimens including orally active derivatives of fluoropyrimidine.

\section{Introduction}

In Japan, gastric cancer is the most common (22.2\%) and colorectal cancer is the second most common (18.1\%) form of cancer (1). The morbidity and mortality rates for gastric cancer peaked in the 1960s, and both rates have since decreased in Japan (2,3). However, the morbidity and mortality rates for colorectal cancer have markedly been increasing (2). Chemotherapy plays an important role in the treatment of gastrointestinal cancers.

5-Fluorouracil (5-FU), which is a frequently used chemotherapeutic drug, was first synthesized by Dushinsky and Heidelberger in 1956 (4). Later, Heidelberger et al reported that 5-FU exhibited an antitumor effect (5). The median survival time of patients with unresectable advanced gastric cancer, which is 3-4 months without any treatment, can be prolonged to 7 months after treatment with 5-FU, 5-FU + doxorubicin, or 5-FU + doxorubicin + mytomycin C (6). Chemotherapy has thus improved the survival time and disease-free period of patients with metastatic colorectal cancer $(7,8)$. Meanwhile, the median survival time of patients with advanced colorectal cancer, which is 6 months without any treatment, can be improved to 10-12 months after treatment with 5-FU or 5-FU + leucovorin (LV) (9).

To select the most appropriate drug for use in individual patients, the utility of anticancer drug sensitivity tests, such as the succinic dehydrogenase inhibition test and the histoculture drug response assay, has been examined. Both of these methods directly judge chemotherapeutic sensitivity by removing cancer cells from the cancer tissues and culturing them with various anticancer drugs. Alternatively, gene expression analyses, which do not require cell culturing with anticancer drugs, for genes related to chemotherapeutic sensitivity have been attracting attention, along with progress in the analysis of the molecular mechanisms of anticancer drug action.

Thymidylate synthase (TS), which is a target enzyme of 5-FU and is also a rate-limiting enzyme in DNA synthesis, 
Table I. Sequences of the PCR primers.

\begin{tabular}{|c|c|c|c|}
\hline $\begin{array}{l}\text { Gene } \\
\text { name }\end{array}$ & $\begin{array}{l}\text { Primer sequence } \\
\text { (forward) }\end{array}$ & $\begin{array}{l}\text { Primer sequence } \\
\text { (reverse) }\end{array}$ & Probe sequence \\
\hline TS & GCCTCGGTGTGCCTTTCA & CCCGTGATGTGCGCAAT & TCGCCAGCTACGCCCTGCTCA \\
\hline DPD & AGGACGCAAGGAGGGTTTG & GTCCGCCGAGTCCTTACTGA & CAGTGCCTACAGTCTCGAGTCTGCCAGTG \\
\hline $\mathrm{TP}$ & CCTTGGATAAGCTGGAGTCTATTCC & CCTGGTCCAGCAGCACTTG & TCAATGTCATCCAGAGCCCAGAGCAGAT \\
\hline FPGS & GGCTGGAGGAGACCAAGGAT & CATGAGTGTCAGGAAGCGGA & CAGCTGTGTCTCCATGCCCCCCTAC \\
\hline GGH & GTGGCAATGCCGCTGAA & CAACTCAGTAGGAAAATTCTGGAACA & TTCACTGGAGGTCAATTGCACAGCAGA \\
\hline DHFR & GTCCTCCCGCTGCTGTCA & GCCGATGCCCATGTTCTG & TTCGCTAAACTGCATCGTCGCTGTGTC \\
\hline ERCC1 & GGGAATTTGGCGACGTAATTC & GCGGAGGCTGAGGAACAG & CACAGGTGCTCTGGCCCAGCACATA \\
\hline Topo1 & TGTAGCAAAGATGCCAAGGT & TGTTATCATGCCGGACTTCT & ССТTСТССТССТСCAGGACATAAGTGGA \\
\hline VEGF & AGTGGTCCCAGGCTGCAC & TCCATGAACTTCACCACTTCGT & TGATTCTGCCCTCCTCCTTCTGCCAT \\
\hline EGFR & TGCGTCTCTTGCCGGAAT & GGCTCACCCTCCAGAAGGTT & ACGCATTCCCTGCCTCGGCTG \\
\hline$\beta$-actin & GAGCGCGGCTACAGCTT & TCCTTAATGTCACGCACGATTT & ACCACCACGGCCGAGCGG \\
\hline
\end{tabular}

and dihydropyrimidine dehydrogenase (DPD), which is related to 5-FU metabolism, have been studied as predictors of prognosis or anticancer drug sensitivity (10-21). These studies on 5-FU-related anticancer drug-sensitivity factors in gastrointestinal cancers are of significance in improving the efficiency of adjuvant chemotherapy for advanced and recurrent cancers and in helping to identify optimal therapies for individual gastrointestinal cancer patients (i.e., establishing customized chemotherapy).

We studied the relationships between the outcomes of gastric and colorectal cancer patients who received treatment with orally active derivatives of fluoropyrimidine after surgery and the expression of genes related to chemotherapeutic sensitivity. Here, we present our findings and discuss the clinical significance of genes related to chemotherapeutic sensitivity.

\section{Materials and methods}

The subjects included 45 patients who underwent adjuvant chemotherapy with orally active derivatives of fluoropyrimidine after undergoing curative surgery between January 2001 and September 2007 in the Department of General and Gastrointestinal Surgery, 2nd Teaching Hospital of Fujita Health University. Of the 45 patients, 21 had gastric cancer and 24 had colorectal cancer. All of the patients received adjuvant chemotherapy with UFT (uracil/tegafur) + oral LV, S-1 (tegafur gimeracil oteracil potassium), or 5-FU. In the UFT + LV regimen, $300 \mathrm{mg} / \mathrm{m}^{2} /$ day of UFT and $75 \mathrm{mg} /$ $\mathrm{m}^{2} /$ day of $\mathrm{LV}$ were divided into three oral doses per day (both agents were administered simultaneously). One course consisted of 4 weeks of medication and 1 week of rest. In the $\mathrm{S}-1$ regimen, $80 \mathrm{mg} / \mathrm{m}^{2} /$ day of $\mathrm{S}-1$ was divided into two oral doses per day. One course consisted of 4 weeks of medication and 2 weeks of rest. In the 5-FU regimen, 200-300 mg/ body/day of 5-FU were divided into three oral doses per day, administered each day.

We prepared formalin-fixed, paraffin-embedded specimens of the resected tumors, and $5-\mu \mathrm{m}$ thick sections were stained with H\&E to identify the cancer cells. Then, isolated cancer cells were removed from $10-\mu \mathrm{m}$ thick sections using the laser-captured microdissection technique (22). Total RNA was extracted and the expression of ten genes [TS, DPD, thymidine phosphorylase (TP), folylpolyglutamate synthetase (FPGS), $\gamma$-glutamyl hydrolase (GGH), dihydrofolate reductase (DHFR), excision repair cross-complementing gene 1 (ERCC1), topoisomerase 1 (Topo1), epidermal growth factor receptor (EGFR) and vascular endothelial growth factor (VEGF)] was measured using the RT-PCR method with a TaqMan probe (Applied Biosystems, Foster City, CA). The expression of $\beta$-actin was also measured as an internal control. The sequence products shown in Table I were used as the primers for TS, DPD, TP, FPGS, GGH, DHFR, ERCC1, Topo1, EGFR, VEGF and $\beta$-actin genes. The expression levels of each gene were normalized using the expression level of $\beta$-actin. PCR was performed using an ABI PRISM 7900 Sequence Detection System (Applied Biosystems). The PCR conditions consisted of 42 cycles at $95^{\circ} \mathrm{C}$ for $15 \mathrm{sec}$ and $60^{\circ} \mathrm{C}$ for $1 \mathrm{~min}$, followed by $50^{\circ} \mathrm{C}$ for $10 \mathrm{sec}$ and $95^{\circ} \mathrm{C}$ for $10 \mathrm{~min}$.

We then analyzed the relationships between the clinicopathological factors, including age, gender, cancer location, pathological type, depth of invasion, lymph node metastasis, stage and site of cancer, and relapse rate, as well as the relationships between the gene expression levels and the relapse rate.

The risk of relapse was evaluated using the Cox proportional hazards model. The cut-off value was determined using the receiver operating characteristic (ROC) curve analysis. The survival rate was calculated using the Kaplan-Meier method. The survival rate was evaluated using the log-rank test, and a p-value of $<0.05$ was considered statistically significant. The statistical analysis software SPSS v.11 (SPSS Japan Inc., Japan) was used for all analyses. This study was approved by the Fujita Health University Ethics Review Board for Epidemiological and Clinical Studies.

\section{Results}

The median observation period was 41 months. Twelve of the 21 gastric cancer patients $(57.1 \%)$ and 11 of the 24 colorectal cancer patients $(45.8 \%)$ relapsed. Although the 
Table II. Univariate analysis of recurrent factors of gastric and colon cancer $(n=45)$.

\begin{tabular}{lcccr}
\hline Variable & Mean \pm SD & Hazard ratio & $95 \%$ CI & P-value \\
\hline TS & $2.53 \pm 1.25$ & 1.047 & $0.746-1.471$ & 0.790 \\
DPD & $0.68 \pm 0.85$ & 0.957 & $0.523-1.749$ & 0.885 \\
TP & $4.96 \pm 3.17$ & 0.996 & $0.869-1.143$ & 0.959 \\
FPGS & $1.44 \pm 1.03$ & 1.047 & $0.720-1.522$ & 0.810 \\
GGH & $2.95 \pm 1.55$ & 1.174 & $0.816-1.689$ & 0.387 \\
DHFR & $2.54 \pm 0.96$ & 0.691 & $0.370-1.291$ & 0.247 \\
ERCC1 & $1.79 \pm 0.80$ & 1.649 & $0.992-2.741$ & 0.054 \\
Topo1 & $1.66 \pm 0.77$ & 1.168 & $0.579-2.357$ & 0.665 \\
VEGF & $6.75 \pm 4.73$ & 0.986 & $0.903-1.077$ & 0.755 \\
EGFR & $3.35 \pm 11.58$ & 0.922 & $0.709-1.199$ & 0.544 \\
\hline
\end{tabular}

Table III. Univariate analysis of recurrent factors of gastric cancer $(n=21)$.

\begin{tabular}{lcccr}
\hline Variable & Mean \pm SD & Hazard ratio & $95 \%$ CI & P-value \\
\hline TS & $2.97 \pm 1.31$ & 0.983 & $0.621-1.556$ & 0.940 \\
DPD & $1.10 \pm 1.05$ & 0.645 & $0.249-1.669$ & 0.366 \\
TP & $6.44 \pm 3.95$ & 0.868 & $0.850-1.147$ & 0.868 \\
FPGS & $1.67 \pm 1.44$ & 0.999 & $0.670-1.489$ & 0.996 \\
GGH & $3.37 \pm 0.78$ & 0.620 & $0.099-3.883$ & 0.609 \\
DHFR & $2.69 \pm 1.22$ & 0.391 & $0.126-1.217$ & 0.105 \\
ERCC1 & $2.08 \pm 0.90$ & 1.237 & $0.626-2.445$ & 0.540 \\
Topo1 & $1.63 \pm 0.95$ & 1.102 & $0.445-2.728$ & 0.834 \\
VEGF & $6.13 \pm 4.99$ & 0.968 & $0.853-1.099$ & 0.620 \\
EGFR & $6.34 \pm 18.38$ & 0.749 & $0.532-1.574$ & 0.749 \\
\hline
\end{tabular}

Table IV. Univariate analysis of recurrent factors of colon cancer $(n=24)$.

\begin{tabular}{lcccr}
\hline Variable & Mean \pm SD & Hazard ratio & $95 \%$ CI & P-value \\
\hline TS & $2.18 \pm 1.10$ & 1.063 & $0.596-1.897$ & 0.836 \\
DPD & $0.26 \pm 0.09$ & 0.157 & $0.000-58.682$ & 0.777 \\
TP & $3.78 \pm 1.70$ & 0.807 & $0.531-1.226$ & 0.314 \\
FPGS & $1.24 \pm 0.39$ & 1.469 & $0.317-6.799$ & 0.623 \\
GGH & $2.82 \pm 1.70$ & 1.243 & $0.844-1.832$ & 0.271 \\
DHFR & $2.46 \pm 0.81$ & 0.997 & $0.423-2.346$ & 0.994 \\
ERCC1 & $1.53 \pm 0.61$ & 3.137 & $1.167-8.431$ & 0.023 \\
Topo1 & $1.69 \pm 0.61$ & 1.387 & $0.479-4.010$ & 0.546 \\
VEGF & $7.24 \pm 4.56$ & 0.823 & $0.896-1.147$ & 0.823 \\
EGFR & $1.45 \pm 2.18$ & 0.911 & $0.641-1.293$ & 0.601 \\
\hline
\end{tabular}

results of a univariate analysis revealed that none of the examined gene expression was related to relapse in the gastric cancer patients, ERCC1 was related to relapse in the colorectal cancer patients [hazard ratio (HR), 3.137; 95\% CI, 1.167-8.431; $\mathrm{P}=0.023$ ] (Tables II-VII). A value of 1.295 was set as the cut-off value for ERCC1 expression based on the results of the ROC curve (Fig. 1); values of $\geq 1.295$ were defined as high expression, while values of $<1.295$ were defined as low expression. Eight of the 12 patients in the highexpression group $(67 \%)$ and 3 of the 12 patients in the low-expression group $(25 \%)$ relapsed. The relapse-free survival rate was lower in the ERCC1 high- than in the ERCC1 low-expression group (HR, 3.891; 95\% CI, 1.023-14.808; $\mathrm{P}=0.046$ ) (Figs. 2 and 3). 
Table V. Univariate analysis of recurrent factors of gastric and colon cancer $(n=45)$.

\begin{tabular}{|c|c|c|c|c|}
\hline Variable & Mean \pm SD & Hazard ratio & $95 \% \mathrm{CI}$ & P-value \\
\hline Age & $64.7 \pm 8.4$ & 0.996 & $0.948-1.047$ & 0.885 \\
\hline Gender (male/female) & $30 / 15$ & 0.961 & $0.405-2.277$ & 0.928 \\
\hline Depth of tumor invasion (sm, mp/ss, se) & $12 / 33$ & 0.535 & $0.182-1.576$ & 0.256 \\
\hline Lymph node metastasis (no/yes) & $5 / 40$ & 1.604 & $0.375-6.853$ & 0.524 \\
\hline
\end{tabular}

Table VI. Univariate analysis of recurrent factors of gastric cancer $(n=21)$.

\begin{tabular}{lcccc}
\hline Variable & Mean $\pm \mathrm{SD}$ & Hazard ratio & $95 \%$ CI & P-value \\
\hline Age & $62.8 \pm 8.7$ & 0.993 & $0.927-1.063$ & 0.830 \\
Gender (male/female) & $16 / 5$ & 0.789 & $0.209-2.973$ & 0.726 \\
Macroscopic type (2/other) & $10 / 11$ & 0.919 & $0.290-2.910$ & 0.886 \\
Histological type (well, moderate/other) & $12 / 9$ & 1.201 & $0.386-3.737$ & 0.752 \\
Depth of tumor invasion (sm, mp/ss, se) & $9 / 12$ & 1.483 & $0.445-4.941$ & 0.521 \\
Pathological stage (II/other) & $7 / 14$ & 1.538 & $0.415-5.693$ & 0.519 \\
\hline
\end{tabular}

Table VII. Univariate analysis of recurrent factors of colon cancer $(n=24)$.

\begin{tabular}{lccc}
\hline Variable & Mean \pm SD & Hazard ratio & $95 \%$ CI \\
\hline Age & $66.4 \pm 7.9$ & 1.009 & $0.938-1.086$ \\
Gender (male/female) & $14 / 10$ & 0.999 & $0.304-3.279$ \\
Organ (colon/rectum) & $15 / 9$ & 0.954 & $0.279-3.262$ \\
Depth of tumor invasion (sm, mp/ss, se) & $3 / 21$ & 0.037 & $0.000-37.694$ \\
Lymph node metastasis (no/yes) & $5 / 19$ & 1.389 & $0.300-6.439$ \\
Pathological stage (II/III) & $5 / 19$ & 1.389 & $0.999-6.439$ \\
\end{tabular}

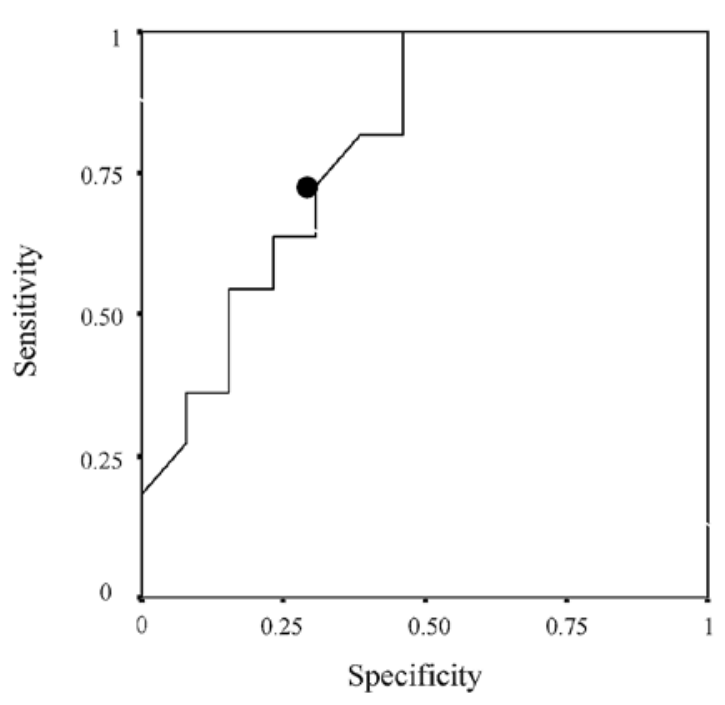

Figure 1. ROC curve showing the sensitivity and specificity of predicting relapse in colorectal cancer patients based on ERCC1 overexpression. The black dot $(\bullet)$ represents the greatest balance between sensitivity and specificity. The black dot, which was regarded as the cut-off point for this analysis, corresponded to an ERCC1 overexpression value of 1.295. The area under the curve (AUC) was 0.797 (95\% CI, 0.620-0.975).

\section{Discussion}

In this study, we analyzed the genes related to chemotherapeutic sensitivity in gastric and colorectal cancer patients who received adjuvant chemotherapy with orally active derivatives of fluoropyrimidine after undergoing curative surgery. We demonstrated that ERCC1 overexpression was related to relapse in colorectal cancer patients.

ERCC1 is a nucleotide excision repair (NER)-related gene which is involved in the excision and repair of damaged DNA. ERCC1 forms a complex with a protein named XRF and repairs DNA interstrand cross-links (23). Since DNA damage induces cell death and gene mutations, the possible causes of aging and carcinogenesis, respectively, DNA repair mechanisms are very important. In platinum-based drugs such as cisplatin, platinum molecules bind to the DNA in tumor cells forming adducts that inhibit DNA replication. This process is considered to be the main molecular mechanism of the antitumor action of these drugs $(23,24)$.

In 1992, Dabholkar et al measured ERCC1 expression in ovarian tumor tissues and reported for the first time in a clinical study that the expression of ERCC1 is related to 


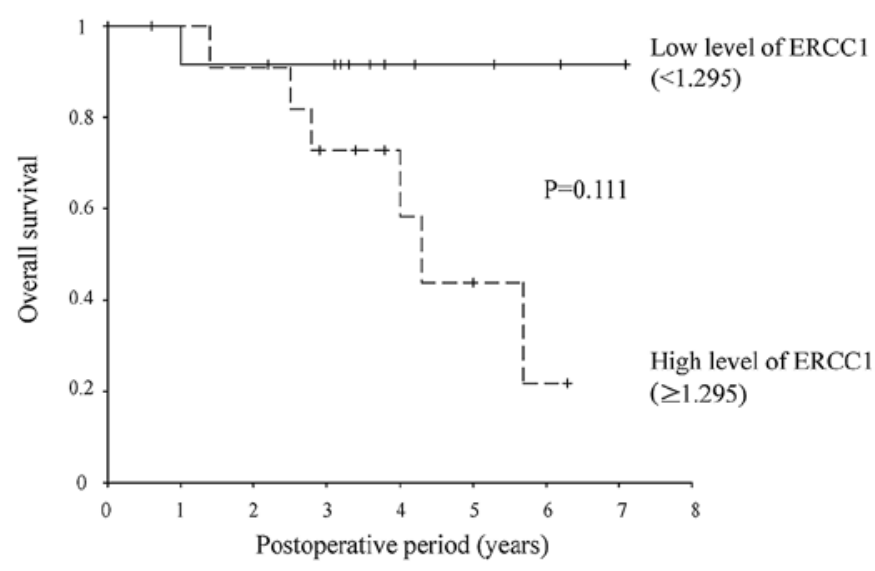

Figure 2. Overall survival of high- and low-expression groups of ERCC1.

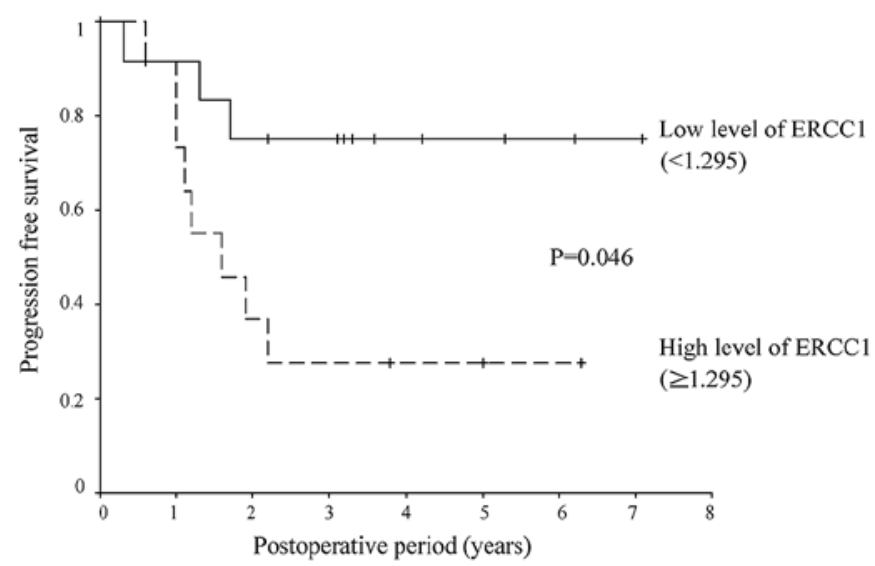

Figure 3. Disease-free survival of high- and low-expression groups of ERCC1.

cisplatin-resistance (25). In vitro studies have also shown that the expression of ERCCl mRNA is related to resistance to platinum-based drugs in cell lines derived from ovarian, head and neck, bladder, testicular and non-small cell lung cancers (24). Additionally, retrospective clinical studies have indicated that the expression of ERCC1 mRNA is related to resistance to platinum-based drugs in gastric, ovarian, colorectal, esophageal and non-small cell lung cancers (24-35). 5-FU + oxaliplatin therapy was administered to patients with advanced gastric cancer, and the expression of ERCC1, TS and glutathione S-transferase P1 (GSTP1) were measured immunohistochemically. Patients with positive ERCC1 expression had a lower overall survival rate (30). In patients with metastatic colorectal cancer who received oxaliplatin + 5-FU combination therapy, ERCC1 overexpression was related to chemotherapeutic resistance and a short survival time, and ERCC1 was suggested to be a potentially useful biomarker (24). In all of these studies, the therapies were performed in combination with platinum-based drugs, while no reports analyzing the relationships between 5-FU monotherapy or orally active derivatives of fluoropyrimidine and ERCC1 were found in a PubMed search.

A relation between ERCC1 expression and CPT-11 sensitivity has also been reported. First-line CPT-11 therapy is effective in colorectal cancers overexpressing ERCC1, EGFR and GSTP1, and the overexpression of both ERCC1 and EGFR has been associated with relapse-free survival (36). ERCC1 and EGFR are expected to be useful for evaluating the response of FOLFIRI and CPT-11 + cetuximab therapies, which are currently administered to patients with unresectable advanced/recurrent colorectal cancer.

5-FU therapy is also effective against metastatic advanced colorectal cancer with low expression levels of intratumoral TS mRNA or protein (10-14). In addition, 5-FU adjuvant chemotherapy is effective against colorectal cancer with a high expression level of intratumoral TS protein (15-19). 5-FU is also effective against advanced head and neck cancer when the expression level of DPD is low (20). Furthermore, the effect of 5-FU therapy can be reportedly predicted by measuring the expression levels of intratumoral TS, TP and DPD in metastatic colorectal cancer (21).

To summarize these numerous reports, since cancer cells overexpressing ERCC1 are adept at repairing DNA damaged by antitumor drugs, patients with such tumors have a high risk of cancer relapse, even after the administration of anticancer drugs. Therefore, ERCC1 might be a useful marker gene for predicting anticancer drug sensitivity. In the cases examined in this study, 1.295 was set as the cut-off value for ERCC1 overexpression based on the results of the ROC curve; values of 1.295 or higher were defined as high-expression, while values less than 1.295 were defined as low-expression. Using this classification, the high-expression patient group was found to have a high risk of relapse. Thus, patients with high intratumoral levels of ERCC1 expression have a higher risk of cancer relapse and should receive frequent follow-up examinations after surgery; additional chemotherapies might also need to be considered.

In conclusion, the overexpression of the ERCC1 gene is useful for predicting relapse in colorectal cancer patients who received adjuvant chemotherapy with orally active derivatives of fluoropyrimidine after undergoing curative surgery.

\section{References}

1. Matsuda T, Marugame T, Kamo K, Katanoda K, Ajiki W, Sobue $\mathrm{T}$ and The Japan Cancer Surveillance Research Group: Cancer incidence and incidence rates in Japan in 2002: based on data from 11 population-based cancer registries. Jpn J Clin Oncol 38: 641-648, 2008.

2. Parkin DM, Whelan SL, Ferlay J, Teppo L and Thomas DB: Cancer incidence in five continents. IARC Scientific Publications no. 155. Vol. 8, Lyon, 2002.

3. WHO databank: http://www.depdb.iarc.fr/who/menu.html

4. Duschinsky R, Pleven E and Heidelberger C: The synthesis of 5-fluoropyrimidines. J Am Chem Soc 79: 4559, 1957.

5. Heidelberger C, Chaudhuri NK, Danneberg P, Mooren D, Griesbach L, Duschinsky R, Schnitzer RJ, Pleven E and Scheiner J: Fluorinated pyrimidines, a new class of tumourinhibitory compounds. Nature 179: 663-666, 1957.

6. MacDonald JS, Schin P, Woolley PV, Smythe T, Ueno W, Hoth D, Smith F, Boiron M, Gisselbrecht C, Brunet R and Lagarde C: 5-Fluorouracil, doxorubicin and mitomycin (FAM) combination chemotherapy for advanced gastric cancer. Ann Intern Med 93: 533-536, 1980.

7. Scheithauer W, Rosen H, Kornek GV, Sebesta C and Depisch D: Randomised comparison of combination chemotherapy plus supportive care with supportive care alone in patients with metastatic colorectal cancer. BMJ 306: 752-755, 1993.

8. Colorectal Cancer Collaborative Group: Palliative chemotherapy for advanced colorectal cancer: systematic review and metaanalysis. BMJ 321: 531-535, 2000. 
9. Meyerhardt JA and Mayer RJ: Systemic therapy for colorectal cancer. N Engl J Med 352: 476-487, 2005.

10. Leichman CG, Lenz H-J, Leichman L, Danenberg K, Baranda J, Groshen S, Boswell W, Metzger R, Tan M and Danenberg PV: Quantitation of intratumoral thymidylate synthase expression predicts for disseminated colorectal cancer response and resistance to protracted-infusion fluorouracil and weekly leucovorin. J Clin Oncol 15: 3223-3229, 1997.

11. Lenz H-J, Hayashi K, Salonga D, Danenberg KD, Danenerg PV, Metzger R, Banerjee D, Bertino JR, Groshen S, Leichman LP and Leichman CG: p53 point mutations and thymidylate synthase messenger RNA levels in disseminated colorectal cancer: an analysis of response and survival. Clin Cancer Res 4: 1243-1250, 1998.

12. Cascinu S, Ashele C, Barni S, Debernardis D, Baldo C, Tunesi G, Catalano V, Staccioli MP, Brenna A, Muretto P and Catalano G: Thymidylate synthase protein expression in advanced colon cancer: correlation with the site of metastasis and the clinical response to leucovorin-modulated bolus 5-fluorouracil. Clin Cancer Res 5: 1996-1999, 1999.

13. Bathe OF, Franceschi D, Livingstone AS, Moffat FL, Tian E and Ardalan B: Increased thymidylate synthase gene expression in liver metastases from colorectal carcinoma: implications for chemotherapeutic options and survival. Cancer J Sci Am 5: 34-40, 1999.

14. Paradiso A, Simone G, Petroni S, Leone B, Vallejo C, Lacava J, Romero A, Machiavelli M, Lena MD, Allegra CJ and Johnson PG: Thymidylate synthase and p53 primary tumor expression as predictive factors for advanced colorectal cancers. Br J Cancer 82: 560-567, 2000.

15. Johnson PG, Fisher ER, Rockette HE, Fisher B, Wolmark N, Drake JC, Chabner BA and Allegra CJ: The role of thymidilate synthase expression in prognosis and outcome of adjuvant chemotherapy in patients with rectal cancer. J Clin Oncol 12: 2640-2647, 1994.

16. Takenoue T, Nagawa H, Matsuda K, Fujii S, Nita ME, Hatano K, Kitayama J, Tsuruo $\mathrm{T}$ and Muto T: Relation between thymidilate synthase expression and survival in colon carcinoma, and determination of appropriate application of 5-fluorouracil by immunohistochemical method. Ann Surg Oncol 7: 193-198, 2000.

17. Elder D, Glimelius B, Hallstrom M, Jakobsen A, Johnson PG, Magnusson I, Ragnhammar P and Blomgren $\mathrm{H}$ : Thymidilate synthase expression in colorectal cancer: a prognostic and predictive marker of benefit from adjuvant fluorouracil-based chemotherapy. J Clin Oncol 20: 1721-1728, 2002.

18. Findlay MPN, Cunningham D, Morgan G, Clinton S, Hardcastle A and Aherne GW: Lack of correlation between thymidylate synthase levels in primary colorectal tumors and subsequent response to chemotherapy. Br J Cancer 75: 903-909, 1997.

19. Ashele C, Debernardis D, Tunesi G, Maley F and Sobrero A: Thymidilate synthase protein expression in primary colorectal cancer compared with the corresponding distant metastases and relationship with the clinical response to 5-fluorouracil. Clin Cancer Res 6: 4797-4802, 2000.

20. Etienne MC, Cheradama S, Fischel JL, Formento P, Dassonville O, Renee N, Schneider M, Thyss A, Demard F and Milano G: Response to flurouracil therapy in cancer patients: the role of tumoral dihydropyrimidine dehydrogenase activity. J Clin Oncol 13: 1663-1670, 1995.

21. Salonga D, Danenberg KD, Johnson M, Metzger R, Groshen S, Tsao-Wei DD, Lenz HJ, Leichman CG, Leichman L, Diasio RB and Danenberg PV: Colorectal tumors responding to 5-fluorouracil have low gene expression levels of dihydropyrimidine dehydrogenase, thymidilate synthase and thymidine phosphorylase. Clin Cancer Res 6: 1322-1327, 2000.

22. Fukui Y, Oka T, Nagayama S, Danenberg PV, Danenberg KD and Fukushima M: Thymidilate synthase, dihydropyrimidine dehydrogenase, orotate phosphoribosyltransferase mRNA and protein expression levels in solid tumors in a large scale population analysis. Int J Mol Med 22: 709-716, 2008.
23. Houtsmuller AB, Rademakers S, Nigg AL, Hoogstraten D, Hoeijmakers JHJ and Vermeulen W: Action of DNA repair endonuclease ERCC1/XRF in living cells. Science 284: 958-961, 1999.

24. Altaha R, Liang X, Yu JJ and Reed E: Excision repair cross complementing-group 1: gene expression and platinum resistance. Int J Mol Med 14: 959-970, 2004.

25. Dabholkar M, Bostick-Bruton F, Weber C, Bohr VA, Egwuagu C and Reed E: ERCC1 and ERCC2 expression in malignant tissues from ovarian cancer patients. J Natl Cancer Inst 84: 1512-1517, 1992.

26. Dabholkar M, Vionnet J, Bostick-Bruton F, Yu JJ and Reed E: Messenger RNA levels of XPAC and ERCC 1 in ovarian cancer tissue correlate with response to platinum-based chemotherapy. J Clin Invest 94: 703-708, 1994.

27. Joshi MB, Shirota Y, Danenberg KD, Conlon DH, Salonga DS, Herndon JE II, Danenberg PV and Harpole DH Jr: High gene expression of TS1, GSTP1 and ERCC1 are risk factors for survival in patients treated with trimodality therapy for esophageal cancer. Clin Cancer Res 11: 2215-2221, 2005.

28. Langer R, Specht K, Becker K, Ewald P, Bekesch M, Sarbia M, Busch R, Feith M, Stein HJ, Siewert JR and Hofler H: Association of pretherapeutic expression of chemotherapy-related genes with response to neoadjuvant chemotherapy in Barrett carcinoma. Clin Cancer Res 11: 7462-7469, 2005.

29. Lord RVN, Brabender D, Gandara D, Alberola V, Camps C, Domine M, Cardenal F, Sanchez JM, Gumerlock PH, Taron M, Sanchez JJ, Danenberg KD, Danenberg PV and Rosell R: Low ERCC1 expression correlates with prolonged survival after ciplatin plus gemcitabine chemotherapy in non-small cell lung cancer. Clin Cancer Res 8: 2286-2291, 2002.

30. Kwon HC, Roh MS, Oh SY, Kim SH, Kim JS and Kim HJ: Prognostic value of expression of ERCC1, thymidylate synthase and glutathione S-transferase P1 for 5-fluorouracil/oxaliplatin chemotherapy in advanced gastric cancer. Ann Oncol 18: 504-509, 2007.

31. Reed E, Dabholkar M, Thornton K, Thompson C, Yu JJ and Bostick-Bruton F: Evidence for in the appearance of mRNAs of nucleotide excision repair genes, in human ovarian cancer tissue. Oncol Rep 7: 1123-1128, 2000.

32. Rosell R, Lord RV, Taron M and Reguart N: DNA repair and cisplatin resistance in non-small cell lung cancer. Lung Cancer 38: 217-227, 2002.

33. Olaussen KA, Dunant A, Fouret P, Brambilla E, Andre F, Haddad V, Taranchon E, Filipits M, Pirker R, Popper HH, Stahel R, Sabatier L, Pignon JP, Tursz T, Chevalier TL and Soria JC: DNA repair by ERCC1 in non-small cell lung cancer and cisplatin-based adjuvant chemotherapy. N Engl J Med 355: 983-991, 2006

34. Shirota Y, Stoehlmacher J, Brabender J, Xiong YP, Uetake H, Danenberg KD, Groshen S, Tsao-Wei DD, Danenberg PV and Lenz HJ: ERCC1 and thymidylate synthase mRNA levels predict survival for colorectal cancer patients receiving combination oxaliplatin and fluorouracil chemotherapy. J Clin Oncol 19: 4298-4304, 2001.

35. Warnecke-Eberz U, Metzger R, Miyazono F, Baldus SE, Neiss S, Brabender J, Schaefer H, Doerfler W, Bollschweiler E, Dienes HP, Mueller RP, Danenberg PV, Hoelscher AH and Schneider PM: High specificity of quantitative excision repair cross-complementing 1 messenger RNA expression for prediction of minor histopathological response to neoadjuvant radiochemotherapy in esophageal cancer. Clin Cancer Res 10: 3794-3799, 2004.

36. Vallbohmer D, Iqbal S, Yang DY, Rhodes KE, Zhang W, Gordon M, Fazzone W, Schultheis AM, Sherrod AE, Danenberg KD and Lenz HJ: Molecular determinants of irinotecan efficacy. Int J Cancer 119: 2435-2442, 2006. 